\title{
Recall, Clustering, and Metamemory in Young Children
}

\author{
Beate Sodian and Wolfgang Schneider \\ Max Planck Institute for Psychological Research, Munich, West Germany
}

AND

\section{Marion Perlmutter}

\author{
University of Michigan
}

\begin{abstract}
Thirty-two 4-year-olds and thirty-two 6-year-olds were tested for free and cued recall following either play-and-remember or sort-and-remember instructions and assessed for their metamemory of the efficacy of conceptual and perceptual sorting strategies. The younger children recalled significantly more items under sort-and-remember than under play-and-remember instructions, whereas no significant recall differences between instructional conditions were found for the older children. However, 6-year-olds showed higher levels of recall than 4-yearolds in both instructional conditions. Category cues were much more effective than color cues, regardless of age. In addition, clustering scores indicated that conceptual organization at both encoding and retrieval increased with age and with instruction. These results show that from 4 to 6 years of age children are learning to spontaneously employ memory strategies. In addition, they highlight the increasing importance of conceptual organization to retention of young children. Finally, the metamemory data suggest that there may be a lag between children's articulated declarative knowledge about the usefulness of conceptual organization and their procedural use of it. () 1986 Academic Press, Inc.
\end{abstract}

Memory development in school children has been studied extensively since the 1960s. Until recently much less attention has been given to the development of memory capabilities prior to school. Preschool children's encoding and retention abilities were traditionally characterized as quite deficient. Recent research has shown, however, that very young children perform remarkably well in quasi-naturalistic memory tasks (e.g., DeLoache, 1980; Nelson \& Ross, 1980; Ratner, 1980; Ratner \& Myers,

The authors thank Karin Hoppe, Ali Sperl, and Maria Zumbeel for their assistance in collecting the data, and the staff of the Kindergarten Allerheiligan and St. Ludwig Kindergarten in Munich, West Germany, for their cooperation. Requests for reprints should be sent to Marion Perlmutter, 300 N. Ingalls, Department of Psychology/Institute of Gerontology, University of Michigan, Ann Arbor, MI 48109-2007. 
1980; Todd \& Perlmutter, 1980; Wellman \& Somerville, 1980). Under certain task situations it appears that even preschool children have some idea of memorization as an active process requiring deliberate effort. When instructed to remember, some investigtors have found that 4-yearolds use mnemonic mediators like naming and visual examination (BakerWard, Ornstein, \& Holden, 1984) and that intentional learning conditions yield better recall even in preschool children than incidental ones (Galbraith, Olsen, Duerden, \& Harris, 1982). In a recent review, Wellman (in press) argues that preschool children's memory activities are truly strategic in the sense that they are deliberate attempts directed at the specific aim to remember.

In spite of the impressive findings on young children's behavior and performance in some memory tasks, work on preschool children's memory has so far not been adequately related to research on memory development in elementary school and older children (Ornstein, Baker-Ward, \& Naus, in press). Little is known, for instance, about the origins of more complex organizational strategies that have been studied extensively in older children's recall. Young elementary school children, when presented with a sort-recall task, typically do not spontaneously sort the items into semantically related groups at encoding, and they show low levels of conceptual clustering in recall. However, elementary school children can be instructed to use organizational strategies, and such organization of items into semantically related groups improves both their recall performance and their level of conceptual clustering in recall (see Moely, 1977; Naus \& Ornstein, 1983; Ornstein \& Corsale, 1979; for reviews).

The first major focus of the present study was to explore the use and effectiveness of organizational strategies in preschool children. Most studies of preschool children's memory performance in sort-recall tasks have investigated the effect of presenting items in semantically related blocks on children's recall performance. Whereas in some studies blocking has been found to increase recall performance in 4- and 5-ycar-olds (Kobasigawa \& Orr, 1973; Morrison \& Lord, 1982; Perlmutter \& Myers, 1979), in other studies there has been no effect of blocking manipulations on young children's recall (Emmerich \& Ackerman, 1978; Garrison, 1980). Only very few studies have investigated the effects of instructing preschool children to use an organizational strategy on their behavior and subsequent recall performance: in an early study, Moely, Olson, Halves, and Flavell (1969) found that 5-year-olds could be trained to arrange pictures into groups by taxonomic class membership and that this manipulation greatly improved their recall performance. Similarly, Lange and Griffith (1977) showed that $4 \frac{1}{2}$-year-olds' recall performance and clustering could be markedly increased by instructing them to organize items into groups and repeating this instruction over several trials until a stable organization had been reached.

These findings indicate that even very young children can be trained 
school children, and poor readers best recall idea units rated as most central to the theme of the passage.

Our results indicate that children's event memory may be represented or reported with respect to a hierarchical organization representing the goal structure of the event. This argument would be strengthened, however, if qualitative aspects of the reports also reflected use of this hierarchy. To this end, an additional analysis was conducted. Differences between the two information levels, superordinate and subordinate, were examined in the overlap of information reported at the first and second interviews. Higher overlap in information reported at two different times would suggest that individuals more stably represent or more consistently search for such information. Thus, for both children and adults overlap would be expected to be higher for the superordinate units if they organize descriptions of events.

Free recall was summed at Times 1 and 2 and the proportions of this total which represented the information units reported during both interviews were calculated separately for make and play, superordinate and subordinate recall. Analyses of variance revealed that there were no age differences in the extent of overlap so the data were combined for the two age groups. As expected, the superordinate actions highest in the hierarchy were most consistently reported. For clay-making information, $61 \%$ of the superordinate and $30 \%$ of the subordinate units were reported at both intervicws. The comparable figures for clay playing were $58 \%$ of the superordinate and $43 \%$ of the subordinate units.

Reports of information varied not only across hierarchial levels but also with respect to the types of connecting links within each event. Both children and adults reported fewer superordinate and subordinate details from the sequentially independent clay-playing event. This suggests that the absence of causal connections between the superordinate nodes influenced subjects' reports. This is consistent with findings from studies of story recall described earlier and indicates that the type of connecting links within an event influences reports of experienced events and stories similarly for both children and adults. Furthermore, developmental differences were more pronounced for reports of the procedural clay-making event than the temporal clay-playing event. This suggests that adults may be better able than children to use the organization present in an event to report its details. Again, however, we must cautiously interpret these findings because so little information was reported, especially from the play event.

\section{Immediate-Delayed Condition versus Delayed-Only Condition}

(Time 2)

In Table 2, the mean proportions of information units reported 7 to 10 days after the event are given. A 2 (Age) $\times 2$ (Condition) $\times 2$ (Sex) 
in preschool children have shown that a basic idea about variables that affect a person's performance in memory tasks is acquired at a remarkably early age (Kreutzer, Leonard, \& Flavell, 1975; Wellman, in press). However, these studies did not address preschool children's knowledge about the effectiveness of organizational strategies, nor are there any studies on the relationship between knowledge about strategy effectiveness, strategy use, and performance in preschool and kindergarten children. We therefore developed a procedure to elicit children's judgments about the effectiveness of a videotaped model's attempts to remember by category sorting, color sorting, randomly sorting, and by merely looking at the items to-be-remembered. We were interested in children's early strategy knowledge and in the correspondence (if any) between the children's own behaviors at encoding and their judgments of the model's behaviors. In order to be able to assess the consistency of children's judgments, two ratings of each of the four behaviors were obtained from each subject, one using the items the subject had previously been tested with and one using a parallel list of items.

\section{METHOD}

\section{Design}

The basic design was a 2 (age) $\times 2($ sex $) \times 2$ (instruction condition) $\times$ 2 (list) $\times 2$ (cue type) factorial design, with the last variable manipulated within subjects. Half of the children in each age group were randomly assigned to a "play-and-remember" condition and the other half to a "sort-and-remember" condition. Half of the subjects in each condition were tested with List 1 and the other half with List 2 . Free recall was always followed by color and category cuing; the order of presenting color vs category cues was counterbalanced across subjects. For the metamemory interview, each subject was shown two films, one showing the list the subject had been tested with and the other one showing the other list. The order of presentation of the two films was counterbalanced across subjects.

\section{Subjects}

The subjects were 64 preschool/kindergarten children ( 33 male and 31 female) living in Munich, West Germany. Thirty-two 4-year-olds were between 45 and 59 months of age (mean age 53 months), and thirty-two 6-year-olds were between 70 and 83 months of age (mean age 75 months).

\section{Materials and Procedures}

The stimuli were small, brightly colored toys, approximately uniform in size. Each of the two lists contained 16 items that were presented from neutral colored boxes. Each list had one red, yellow, green, and blue item from each of the four categories (animals, furniture, household 
items, and gardening items in List 1; vehicles, writing objects, tools, and cutlery items in List 2). The items in List 1 were a blue elephant, green dog, yellow cow, red horse, blue wardrobe, green chair, yellow table, red bed, blue teapot, green frying pan, yellow cup, red pot, blue rake, green bucket, yellow shovel, and red watering-can. The items in List 2 were a blue bus, green tractor, yellow truck, red car, blue pencil sharpener, green ruler, yellow eraser, red pencil, blue pliers, green screwdriver, yellow hammer, red wrench, blue knife, green fork, yellow ladle, and red spoon. Subjects were tested individually in a quiet room in their kindergarten.

\section{Memory Task}

Presentation phase. After a brief introductory period, the experimenter gave the following instructions: "I have a box full of toys (shaking the box). Do you want to see the toys? I am going to show you the toys now."

The items in each list were always presented in the same random order, which was constrained so that no adjacent items were of the same color or from the same conceptual category. In presenting each item the experimenter took a single toy from the box and asked the child to label it. If the child did not do so correctly the experimenter provided the label and asked the child to repeat it. After the child produced a correct label, the experimenter repeated it. The items were arranged in a semicircle on a $(45-\times 60-\mathrm{cm})$ white board.

Instructional conditions. After all the toys were presented, the experimenter gave the following instructions:

Play and remember. I will leave the toys for you now and you can play with
them. Later on I will hide them in the box and ask you to tell me what toys you
saw. Do you understand? First you play with the toys and then I will hide them
and we will see what you remember. You can do anything you like with the toys,
anything that will help you recall as many toys as possible.

Sort and remember. I will leave the toys for you now and you can to play a game with them. The game is to put all those toys together that go together. Later on I will hide them in the box and ask you to tell me what toys you saw. Do you understand? First you put all those toys together that go together/that are alike and then I will hide them and we will see what you remember.

Play/sort phase. Children were allowed to play with the objects or to sort them for $2 \mathrm{~min}$. The experimenter coded cach child's behavior according to the following categories: sorts by color, by category, mixed sorting, sorts by another criterion (which was specified), or does not sort. Any comments by the child were noted, and an overall description of the child's behavior during play or sorting was recorded. After 2 min 
a color photograph that showed the final arrangement of the objects was taken. Then the toys were hidden.

Free recall phase. The child was asked to "tell the names of all the toys you have seen." When the child ceased to volunteer additional responses the experimenter asked the child to "try to see if you can remember any more toys." When the child seemed unable to recall any more items a cuing procedure was initiated.

Cued recall phase. A doll was introduced to the child who "was very curious to know all the toys the child had seen before." For color cuing the doll initiated the procedure by asking the child to tell her "all the names of the red toys you saw"; for category cuing the doll asked for "all the names of the animals." Two different dolls were used for color and category cuing in order to motivate the child to tell all the names once more. The cues were presented in two different random orders.

Color and category check. After all the memory tests the child's knowledge of the color and category labels was checked. The objects were shown to the child once more and she or he was asked to point to all the animals/vehicles/household items, etc.. and to point to all the red, blue, green, and yellow objects. The objects were then removed from view and the metamemory task was introduced.

\section{Metamemory Task}

For the metamemory interview a 5-year-old female model named Lindi was videotaped while performing four different sorting behaviors on the items of each of the two lists. In each scene the objects were first shown arranged in a semicircle in front of the model for about $10 \mathrm{~s}$. Then the sorting behavior was filmed from behind the model's shoulder. The scenes were each 1 min long.

Sorting styles. The four different sorting styles were as follows: random sorting: the model arranged the objects randomly in groups of four in the four corners of the table; color sorting: the model arranged the objects by color in the four corners of the table; category sorting: the model arranged the objects by conceptual category in the four corners of the table; no sorting (looking at the objects): the model left the objects in the original arrangement and looked at them attentively one-by-one from left to right.

Interview. The experimenter gave the following instructions in introducing the film:

I am going to show you a film on TV. The child in the film is named Lindi. She is your age. In the film you will see Lindi playing with the toys. Some games are good for helping Lindi to remember many toys, but some games are not so good. After each game I will stop the film and ask you whether the game Lindi played is good for helping her to remember the toys or whether it is not so good. Then I will start the film again and we will look at the next game. Do you understand? 
The four scenes for each list were always shown in the same random order. After each scene the experimenter stopped the film and asked the child what Lindi had done with the toys. If the child did not come up with a correct description spontaneously, the experimenter explicated it for the child. For example, she may have pointed out that Lindi put all the red things together, all the blue things together, etc. The child was asked to confirm this description. Then the experimenter asked the following questions: (1) when you were playing with the toys, did you play with them the same way that Lindi did or did you play with them in a different way? (2) When the toys are hidden and Lindi has to tell all the toys she has seen, will she remember the toys well, will she remember them just a little, or will she remember them badly? What do you think?

\section{RESULTS}

Preliminary analysis of the dependent measures revealed no systematic effects of sex or list. Furthermore, no order effects were found for the two stimulus lists used in the metamemory interview or for the two cue types (color-category vs category-color) used for cuing recall. Thus, the data were collapsed across these variables.

\section{Free Recall}

Table 1 shows the mean number of items correctly recalled in the play-and-sort instruction conditions separately for each group. Inspection of these data suggests that 6-year-olds recalled more than 4-year-olds under both instructional conditions. However, the younger children seemed to benefit more from the sort-and-remember instructions. The statistical analyses confirmed this impression. Results of a 2 (age) $\times 2$ (instructional condition: Sort and Remember vs Play and Remember) analysis of ariance revealed significant main effects of age $(F(1,60)=16.21, p<.05)$ and instructional condition $(F(1,60)=11.61, p<.01)$ and a significant age $\times$ instructional condition interaction $(F(1,60)=4.70, p<.05)$. Younger children recalled fewer items than older children ( 7.84 vs 10.69$)$, and the

TABLE 1

Mean Number of Items Correctly Recalled in Free Recall in the Play-andRemember and Sort-and-Remember Instruction Conditions by Each Age Group

\begin{tabular}{lcc} 
& \multicolumn{2}{c}{ Instructional condition } \\
\cline { 2 - 3 } Age group & Play and remember & Sort and remember \\
\hline 4-year-olds & 5.87 & 9.81 \\
- & $(3.32)$ & $(3.03)$ \\
6-year-olds & 10.25 & 11.13 \\
& $(2.32)$ & $(2.50)$ \\
\hline
\end{tabular}

Note. Standard deviations in parentheses. 
mean number of items correctly recalled in the sort condition was more than in the play condition (10.47 vs 8.06 ). In addition, simple effects $t$ tests indicated that for the younger children performance was significantly better in the sort-and-remember condition than in the play-and-remember condition $(t(30)=3.50, p<.01)$, while for older children this difference was not statistically significant $(t(30)=1.02, p<.10)$.

\section{Cued Recall}

The mean number of items correctly recalled after categorical cuing is depicted in Table 2 . A 2 (age) $\times 2$ (instructional conditions) ANOVA yielded significant main effects for age $(F(1,60)=14.16, p<.01)$ and instructional condition $(F(1,60)=4.03, p<.05)$. The older children recalled more than the younger children, and children in the sort-andremember group remembered more than children in the play-and-remember group. The age $\times$ condition interaction was only marginally significant $(F(1.60)=2.80, p<.10)$. While for the younger subjects the sort-andremember condition seemed to lead to better recall than the play-andremember condition, almost no recall differences between the two instructional conditions were observed in the older children.

Since list items were orthogonally varied in terms of category and color, the effect of color cuing on recall was also assessed. Here only the main effect of age proved statistically significant $(F(1.60)=6.19, p$ $<.05$ ). Older subjects recalled significantly more items than younger subjects (5.84 vs 4.46$)$. Neither the main effect of instructional condition nor the age $\times$ instructional condition interaction approached significance. Categorical cuing was more effective than color cuing in both age groups (8.63 vs 4.46 and 11.43 vs 5.84 for the younger and older children, respectively).

\section{Organization during Encoding}

In order to assess the degree of color and category organization during encoding in the two instructional conditions, the photographs showing

TABLE 2

Mean Number of Items Correctly Recalled after Categorical Cuing in the Play-

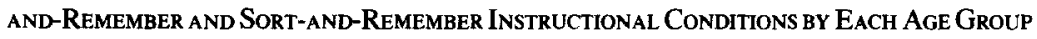

\begin{tabular}{lcc} 
& \multicolumn{2}{c}{ Instructional condition } \\
\cline { 2 - 3 } Age group & Play and remember & Sort and remember \\
\hline 4-year-olds & 7.25 & 10.0 \\
& $(3.17)$ & $(3.03)$ \\
6-year-olds & 11.31 & 11.56 \\
& $(2.93)$ & $(2.80)$ \\
\hline
\end{tabular}

Note. Standard deviations in parentheses. 
the final arrangement of the objects (after the 2-min play or sort period) were analyzed using a procedure first developed by Kee and Bell (1981). A ratio of repetition ( $R R$ ) measure with a maximum value of slightly less than 1.0 and a minimum value of zero (see Bousfield \& Bousfield, 1966) was computed for both category and color clustering. This measure has been shown statistically to be relatively independent of the level of total recall and of the size and numbers of categories recalled (cf. Murphy \& Puff, 1982).

Mean RR clustering scores for color and category organization in the two instructional conditions $\times$ each age group are shown in Table 3 . Inspection of these data suggestions that the two age groups did not differ with regard to color organization and that instructional conditions did not influence the degree of color clustering. The small RR scores indicate that clustering was around or below chance level. On the other hand, older children showed more categorical clustering, and RR scores above chance level were only obtained in the sort-and-remember instructional condition.

These impressions were confirmed by the statistical analyses. In the ANOVA carried out on the color clustering scores neither the main effect of age nor that of instructional condition approached significance, and the age $\times$ instructional condition interaction also proved nonsignificant. However, there was a statistically significant age main effect on the category clustering scores, $F(1,60)=4.78, p<.05$, and also a significant instructional condition main effect, $F(1,60)=30.65, p<.01$. The age $\times$ instructional condition interaction was not statistically significant.

As an additional measure of organization, during encoding the experimenter and an independent observer rated each subject's behavior according to the following categories: sorts by color, sorts by conceptual category, and does not sort (preserves the original order). Both the protocol notes of the child's behavior during the play-sort phase and

TABLE 3

Mean Color and Category Encoding RR Scores in the Play-and-Remember and Sort-and-Remember Instructional Conditions by Each Age Group

Instructional condition

\begin{tabular}{lccccc} 
& \multicolumn{2}{c}{ Play and remember } & \multicolumn{2}{c}{ Sort and remember } \\
\cline { 2 - 3 } Age group & Color RR & Category RR & Color RR & Category RR \\
\hline 4-year-olds & .06 & .13 & .12 & .46 \\
& $(.09)$ & $(.17)$ & $(.20)$ & $(.25)$ \\
6-year-olds & .10 & .27 & .11 & .57 \\
& $(.10)$ & $(.28)$ & $(.16)$ & $(.20)$
\end{tabular}

Note. Standard deviations in parentheses. 
the photograph showing the final arrangement of items were taken into account. Interrater reliability was .90 .

Table 4 shows the number of children in each age group who sorted by color, by conceptual category, or who did not sort. Also indicated is the mean number of items recalled in free recall for children in each of these sorting categories.

These data confirm the impressions conveyed by the RR scores. Almost none of the subjects in either age group arranged the objects by color. Whereas in the sort-and-remember condition almost all the children, regardless of age, grouped the objects according to their category membership, in the play-and-remember condition almost half of the children did not organize the mterial at all, but rather most looked at the objects or manipulated them one by one. This behavior was shown equally often by 4-year-olds and 6-year-olds; however, the older "non-sorters" mean recall scores were more than twice as high as the younger children's.

\section{Organization During Recall}

Mean RR clustering scores for color and category recall organization in the two instructional conditions by each age group may be seen in Table 5. Similar to the findings obtained for encoding, color clustering scores during retrival were small and at chance level, regardless of age and instructional condition. On the other hand, younger and older children's category clustering scores were significantly above change level, and the age difference in these scores was statistically significant $(F(1,60)=$ $4.03, p<.05)$. There was a significant effect of instructional conditions on category clustering $(F(1,60)=14.49, p<.01)$. Both age groups demonstrated more category clustering in the sort-and-remember (.69)

TABLE 4

Mean Recall in the Play-and-Remember and Sort-And-Remember Instructional Conditions by Sorting Behavior, Separately for Four- and Six-Year-Olds

Instructional condition

\begin{tabular}{lccccccc} 
& \multicolumn{3}{c}{ Play and remember } & & \multicolumn{2}{c}{ Sort and remember } \\
$\begin{array}{l}\text { Sorting } \\
\text { behavior: } \\
\text { Age group }\end{array}$ & Color & Category & $\begin{array}{c}\text { No apparent } \\
\text { sorting }\end{array}$ & & Color & Category & $\begin{array}{c}\text { No apparent } \\
\text { sorting }\end{array}$ \\
\hline 4-year-olds & - & 8.2 & 3.9 & & 5.0 & 10.2 & 3.0 \\
& $(0)$ & $(8)$ & $(7)^{a}$ & & $(1)$ & $(14)$ & $(1)$ \\
6-year-olds & - & 11.9 & 9.1 & & 7.0 & 11.3 & - \\
& $(0)$ & $(9)$ & $(7)$ & & $(1)$ & $(5)$ & $(15)$
\end{tabular}

Note. Number of children showing each of the four sorting behaviors in parentheses.

${ }^{a}$ One subject's behavior could not be classified. 
TABLE 5

Mean Color and Category RR Scores for Recall Protocols in the Play-andRemember and SORT-AND-REMEMBer INSTRUCTIONAL Conditions by Each Age Group

\begin{tabular}{lcccc}
\hline & \multicolumn{4}{c}{ Instructional condition } \\
\cline { 2 - 5 } Age group & \multicolumn{2}{c}{ Play and remember } & \multicolumn{2}{c}{ Sort and remember } \\
\cline { 2 - 5 } 4-year-olds & .09 & Category RR & Color RR & Category RR \\
6-year-olds & $(.14)$ & .31 & .08 & .53 \\
& .12 & $(.22)$ & $(.10)$ & $(.22)$ \\
& $(.13)$ & .44 & .11 & .62 \\
& & $(.22)$ & $(.08)$ & $(.14)$ \\
\hline
\end{tabular}

than in the play-and-remember (.40) instructional condition. No significant interaction on category clustering was found.

\section{Metamemory}

In order to assess subjects' judgments concerning the utility of the conceptual sorting, color sorting, random sorting, and looking strategies demonstrated by the model, the children's responses were scored on a three-point rating scale. Three points were given whenever the child expected the film model to remember well. Two points were given when the child thought the strategy in question to be of limited value ("just so-so") for remembering, and one point was given whenever the child expected the model to remember the items badly. The sum scores across the two lists obtained for the four strategies ranged between two and six points. It should be noted that consistency of judgments across the two lists varied with age. Only about $50 \%$ of the 4-year-olds, but nearly $80 \%$ of the 6-year-olds, showed high consistency across the lists (i.e., their ratings of corresponding strategies did not differ by more than one point) and did not judge stereotypically (i.e., they judged the strategies differently with regard to efficacy).

Mean efficacy ratings for the four strategics are shown in Table 6.

TABLE 6

Mean Efficacy Ratings for the Four Sort Strategies Used by the Model by Each Age Group

\begin{tabular}{lcc} 
& & \\
& & Age \\
\cline { 2 - 3 } Strategy & 4-year-olds & 6-year-olds \\
\hline Looking & 4.26 & 4.15 \\
Random sorting & 3.87 & 3.31 \\
Color sorting & 4.36 & 4.65 \\
Conceptual sorting & 3.80 & 4.59
\end{tabular}


Statistical analyses yielded neither a significant instructional condition main effect nor interaction involving instruction. Thus the data were collapsed across instructional conditions. As can be seen from Table 6, the two ages did not differ remarkably with regard to their efficacy judgments. Results of a multivariate analysis of variance (MANOVA) using age as the independent variable and efficacy judgments for sorting by color indicated that older children judged conceptual sorting more effective than younger children $(F(1,16)=4.35, p<.05)$.

A subsequent MANOVA using age as an independent variable and judgments of "good," "just so-so," and "bad" (collapsed across Lists 1 and 2) for sorting by color, by category, random sorting, and looking as the dependent variable confirmed this finding. The only significant main effect of age concerned the "good" judgments for sorting by category $(F(1,60)=4.16, p<.05)$. More older than younger children judgged sorting by category a good strategy.

Interrelations among Recall, Clustering, and Metamemory

Table 7 contains the intercorrelations among free recall, conceptual clustering, and metamemory scores for conceptual sorting. As can be seen from Table 7 , conceptual clustering during encoding was significantly related to conceptual clustering during recall as well as to recall performance for both age groups.

Developmental trends were found for the relationships between free recall and subjects' preference for conceptual sorting, and for the relationship between conceptual sorting and subjects' preference for conceptual sorting. In both cases, no relationship could be detected for the 4-yearolds, but significant correlations existed for the 6-year-olds. It should be noted that color clustering during sorting and during recall as well as

TABLE 7

Intercorrelations among Free Recall, Conceptual Clustering, and Metamemory by Each Age Group

\begin{tabular}{lccc} 
& $\begin{array}{c}\text { Conceptual } \\
\text { clustering } \\
\text { (encoding) }\end{array}$ & $\begin{array}{c}\text { Conceptual } \\
\text { clustering } \\
\text { (recall) }\end{array}$ & $\begin{array}{c}\text { Preference for } \\
\text { conceptual } \\
\text { clustering }\end{array}$ \\
\hline Free recall & $.68^{*}$ & .27 & -.18 \\
$\begin{array}{l}\text { Conceptual clustering } \\
\text { (encoding) }\end{array}$ & $(.48)^{*}$ & $(.44)^{*}$ & $(.37)^{*}$ \\
Conceptual clustering & .32 & .03 \\
(recall) & $(.65)^{*}$ & $(.37)$ \\
\hline
\end{tabular}

Note. Values for 6-year-olds in parentheses.

* Correlations significant at the .05 level. 
subjects' preference for color sorting did not relate to recall, regardless of age.

\section{DISCUSSION}

The main purpose of this study was to assess young children's sorting behavior and their recall performances in a sort-recall task under two different instructional conditions.

The results indicated that 4-year-olds', but not 6-year-olds', recall performance is superior after a sort-and-remember instruction than after a play-and-remember instruction. In both age groups the level of categorical sorting (encoding) was higher in the "sort" condition than in the "play" condition. There was also a significant main effect of instruction condition on category clustering in recall. Both age groups demonstrated more category clustering in the "sort" than in the "play" condition. In the "sort" condition even 4-year-olds' clustering scores were well above chance level both during encoding and during recall.

In contrast to previous findings on young children's sorting criteria, the younger children in this study did not rely more on perceptual than on conceptual relations among items. The scores for color clustering both during encoding and during recall did not differ from chance level for either age group. Only one child's behavior in each age group was classified as "sorting by color." In both conditions and for both age levels, color cues proved much less effective in aiding recall than category cues. This finding is somewhat surprising, as previous research (Perlmutter \& Ricks, 1979) has indicated that the percentage of children who use color as a criterion for sorting is substantial (47\%) among 4-year-olds. In the Perlmutter and Ricks study children were asked to sort the objects only after having completed a series of memory tasks that included both color and category cuing. Thus, their sorting behavior was not associated with instructions to remember, but may have been influenced by the classification criteria provided by the experimenter during the memory tasks.

When asked to sort spontaneously, even 4-year-olds seemed to rely exclusively on the conceptual relations between the objects. Sorting the objects by conceptual category seemed to improve 4-year-olds' recall performance substantially, as indicated by the superiority of the "sort" condition over the "play" condition. This pattern did not, however, hold for 6-year-olds: their recall performance in the "play" condition was quite high (although well below ceiling) and did not differ significantly from the "sort" condition. The age $\times$ instruction condition interaction could be readily explained if the 6-year-olds' level of category sorting were as high in the "play" condition as in the "sort" condition, that is, if they spontaneously arranged objects by conceptual category in the play condition. The results indicate that a higher level of conceptual 
organization during encoding accounts only partly for the older children's better recall in the play condition (see Tables 3 and 4). The proportion of children in the "play" condition who simply looked at the objects without any attempt at arranging them in groups was the same for both age groups. Six-year-olds, however, recalled more than twice as many items after "looking" than did 4-year-olds.

Older children may be better able than younger children to make use of the conceptual relations between encoding without openly manipulating them. They may also have been more attentive and more motivated than the younger children. In summary, then, we have been able to show that even very young children's recall performance can be improved by instructing them to use an organization strategy (i.e., sorting). The age $x$ instruction condition interaction indicates, however, than other factors besides the more efficient use of organizational strategies have to be considered in order to account for developmental progress in young children's recall performance.

An additional purpose of this study was to test young children's declarative knowledge about the effectiveness of different memory strategies. In the metamemory interview, highly consistent judgments were only obtained from the older children. The results indicate that 6-year-olds prefer conceptual organization significantly more than 4-year-olds. However, they do not rate sorting by color as a bad strategy when asked to judge a model's behavior. These results may be interpreted as supporting the view that young children make use of conceptual relations between items but that they do not know about the functional value of this strategy (compared to perceptual grouping or looking) in memory tasks (cf. Perlmutter, 1984). However, the failure to discriminate between different memory strategies also may be due to the assessment technique that was used: young children may find it very difficult to judge different behaviors in absolute terms. Pairwise comparisons between different strategies might be a more useful technique to elicit metamemory judgments from young children.

In conclusion, this research illuminates some of the ways in which memory improves during the early childhood years. Significant age $\times$ instruction interactions in both free and cued recall indicated that from 4 to 6 years of age children are learning to employ spontaneous memory strategies to enhance their remembering. The importance of conceptual organization to this process was highlighted by the encoding and retrieval clustering data. Even at the younger age level, children were able to organize information conceptually when so instructed, and this organization improved their performance. On the other hand, at the older age level, even without instruction, children used some conceptual organization to aid memory. With conceptual organization instructions, their performance improved, but the degree of improvement was less than for the younger 
children. The metamemory assessment also was informative. The rather limited discrimination of the efficacy of conceptual and perceptual organization that was observed suggests a lag between children's articulated, declarative knowledge about conceptual organization and their procedural use of it.

\section{REFERENCES}

Baker-Ward, L., Ornstein, P. A., \& Holden, D. J. (1984). The expression of memorization in early childhood. Journal of Experimental Child Psychology, 37, 555-575.

Bousfield, A. K., \& Bousfield, W. A. (1966). Measurement of clustering and of sequential constancies in repeated free recall. Psychological Reports, 19, 935-942.

Cavanaugh, J. C., \& Perlmutter, M. (1982). Metamemory: A critical examination. Child Development, 53, 11-28.

Ceci, S. J., Lea, S. E. G., \& Howe, M. J. A. (1980). Structural analysis of memory traces in children from 4 to 10 years of age. Developmental Psychology, 16, 203-212.

DeLoache, J. S. (1980). Naturalistic studies of memory for object location in very young children. In M. Perlmutter (Ed.), Children's memory. San Francisco: Jossey-Bass.

Emmerich, H. J., \& Ackerman, B. P. (1978). Developmental differences in recall: Encoding or retrieval? Journal of Experimental Child Psychology, 25, 514-525.

Galbraith, R. C., Olsen, S. F., Duerden, D. S., \& Harris, W. L. (1982). The differentiation hypothesis: Distinguishing between perceiving and memorizing. American Journal of Psychology, 95, 655-667.

Garrison, A. (1980). Categorical and spatial modes of representation in young children's recall. Journal of Experimental Child Psychology, 30, 383-388.

Kee, D. W., \& Bell, T. S. (1981). The development of organizational strategies in the storage and retrieval of categorical items in free recall learning. Child Development, 52, 1163-1171.

Kobasigawa, A., \& Orr, R. (1973). Free recall and retrieval speed of categorized items by kindgarten children. Journal of Experimental Child Psychology, 15, 187-192.

Kreutzer, M. A., Leonard, C., \& Flavell, J. H. (1975). An interview of children's knowledge about memory. Monographs of the Society for Research in Child Development, 40 (1, Serial No. 159).

Lange, G., \& Griffith, S. B. (1977). The locus of organization failures in children's recall. Child Development, 48, 1498-1502.

Melkman, R., Tversky, B., \& Baratz, D. (1981). Developmental trends in the use of perceptual and conceptual attributes in grouping, clustering, and retrieval. Journal of Experimental Child Psychology, 31, 470-486.

Moely, B. E. (1977). Organizational factors in the development of memory. In R. V. Kail, Ir., \& J. W. Hagen (Eds.), Perspectives on the development of memory and cognition. Hillsdale, NJ: Erlbaum.

Moely, B. E., Olson, F. A., Halves, T. G., \& Favell, J. H. (1969). Production deficiency in young children's clustered recall. Developmental Psychology, 1, 26-34.

Morrison, F. J., \& Lord, C. (1982). Age differences in recall of categorized material: Organization or retrieval? Journal of Genetic Psychology, 141, 233-241.

Murphy, M. D., \& Puff, C. R., (1982). Free recall: Basic methodology and analyses. In C. R. Puff (Ed.), Handbook of research methods in human memory and cognition. New York: Academic Press.

Naus, M. J., \& Ornstein, P. A. (1983). Development of memory strategies: Analysis, questions, and issues. In M. T. H. Chi (Ed.), Trends in memory development research. Basel: Karger. 
Nelson, K., \& Ross, G. (1980). The generalities and specifics of long-term memory in infants and young children. In M. Perlmutter (Ed.), Children's memory. San Francisco, CA: Jossey-Bass.

Ornstein, P. A., \& Corsale, K. (1979). Organizational factors in children's memory. In C. R. Puff (Ed.), Memory organization and structure. New York: Academic Press.

Ornstein, P. A., Baker-Ward, L., \& Naus, M. J. (in press). The development of mnemonic skill. In F. E. Weinert \& M. Perlmutter (Eds.), Memory development: Universal changes and individual differences. Hillsdale, NJ: Erlbaum.

Perlmutter, M. (1984). Continuities and discontinuties in early human memory paradigms, processes, and performance. In R. Kail \& N. V. Spear (Eds.), Comparative perspectives in the development of memory. Hillsdale, NJ: Erlbaum.

Perlmutter, M., \& Myers, N. A. (1979). Recall development in two- to four-year-olds. Developmental Psychology, 15, 73-83.

Perlmutter, M., \& Ricks, M. (1979). Recall in preschool children. Journal of Experimental Child Psychology, 27, 423-436.

Piaget, J. (1970). J. Piaget's theory. In P. H. Mussen (Ed.), Carmichael's manual of child psychology (Vol. 1). New York: Wiley.

Ratner, H. H. (1980). The role of context in memory development. In M. Perlmutter (Ed.), Children's memory. San Francisco, CA: Jossey-Bass.

Ratner, H. H., \& Myers, N. A. (1980). Related picture cues and memory for hidden-object locations at age two. Child Development, 51, 561-564.

Schneider, W. (1985). Developmental trends in the metamemory-memory behavior relationship: An integrative review. In D. L. Forrest-Pressley, G. E. MacKinnon, \& T. G. Waller (Eds.), Cognition, metacognition, and human performance (Vol. 1, pp. 57109). New York: Academic Press.

Todd, C. M., \& Perimutter, M. (1980). Reality recalled by preschool children. In M. Perlmutter (Ed.), Children's memory. San Francisco, CA: Jossey-Bass.

Wellman, H. M. (1983). Metamemory revisited. In M. T. H. Chi (Ed.), Trends in memory development research. Basel: Karger.

Wellman, H. M. (in press). The early development of memory strategies. In F. E. Weinert \& M. Perlmutter (Eds.), Memory development: Universal changes and individual differences. Hillsdale, NJ: Erlbaum.

Wellman, H. M., \& Somerville, S. G. (1980). Quasi-naturalistic tasks in the study of cognition: The memory-related skills of toddlers. In M. Perlmutter (Ed.), Children's memory. San Francisco: Jossey-Bass.

RECEIVED: May 28, 1985; REVISED: November 11, 1985. 